\title{
O exercício da autoridade em famílias com filhos adolescentes
}

The use of authority in families with adolescent children

El uso de autoridad en las familias con hijos adolecentes

Márcia Stengel *

\begin{abstract}
Resumo
Importantes transformações vêm se dando no interior da família contemporânea, mudanças estas que se tornam mais visíveis na adolescência dos filhos. Um ponto de impacto dessas mudanças localiza-se no relacionamento paterno-filial. Nesse cenário, o exercício da autoridade tem sido percebido como cada vez mais complexo, com os desafios, impasses e dificuldades que se apresentam. Com base em pesquisa qualitativa com entrevistas em profundidade com pais e mães de adolescentes, casados e separados, de camada média, este artigo debate como esse exercício se apresenta. Como uma das tarefas dessa fase é a construção da identidade adulta, o adolescente deve renunciar aos papéis infantis, abarcando o abandono de um tipo de relação estabelecida com os pais. Esse processo demanda modificações na família, havendo necessidade de adaptação das regras e, consequentemente, de ajustamento no exercício da autoridade. Os pais precisam buscar formas de manter a autoridade em um contexto familiar mais igualitário.
\end{abstract}

Palavras-chave: Família, adolescência, autoridade, pais de adolescentes.

\begin{abstract}
Important changes have been occurring within the contemporary family, changes that have become more visible in the adolescence of children. A point of impact of these changes is located in the paternal-filial relationship. In this scenario, the use of authority has been perceived as increasingly complex, considering the challenges and dilemmas that arise. From a qualitative study based on in depth interviews with parents of teenagers, married and separated, from the middle social layer, this article discusses how this use of authority has been performed and transformed. As one of the tasks of this phase is the construction of adult identity, the adolescent must relinquish the roles for children, covering
\end{abstract}

\footnotetext{
Texto recebido em outubro de 2011 e aprovado para publicação em janeiro de 2012.

Doutora em Ciências Sociais pela UERJ e professora do Programa de Pós-graduação em Psicologia da PUC Minas. E-mail: marciastengel@gmail.com.
} 
the abandonment of one kind of relationship established with parents. This process demands changes, requiring adjustment of the rules and, therefore, adjustment in the exercise of authority. In this context, parents need to find ways of maintaining order in a more egalitarian family context.

Keywords: Family, adolescence, authority, parents of teenager.

\section{Resumen}

Transformaciones ven si dando dentro de la familia, estos cambios se hacen más visibles en la adolescencia de los niños. Un punto de impacto de estos cambios se encuentra en la relación paterna-filial. En este escenario, el ejercicio de autoridad ha sido percibido como desafíos complejos y dificultades que se presentan. De investigación cualitativa con entrevistas con padres y madres de los adolescentes, casados y separados, nivel medio, este artículo describe cómo este ejercicio presenta. Como una de las tareas en esta fase es la construcción de la identidad adulta, el adolescente debe renunciar a las funciones de niño que cubre el abandono de un tipo de relación establecida con los padres. Este proceso exige cambios en la familia, la necesidad de adaptar las normas y lo ajuste en el ejercicio de autoridad. Los padres deben buscar formas de mantener la autoridad en un contexto familiar más igualitaria.

Palabras-clave: Familia, adolescencia, autoridad, padres de adolescentes.

ste artigo objetiva discutir o exercício da autoridade em famílias com filhos adolescentes. Este tem sido percebido como cada vez mais complexo, com os desafios, impasses e dificuldades que se apresentam, especialmente pelas importantes transformações que vêm se dando no interior da família contemporânea.

Os processos psíquicos e sociais que os adolescentes vivem trazem modificações na família, havendo necessidade de adaptação das regras e, consequentemente, de ajustamento no exercício da autoridade. Há que se considerar esse exercício articulado com a estrutura familiar, bem como o desempenho dos papéis parentais, que se modificaram bastante nas últimas décadas.

\section{A família contemporânea: algumas considerações}

Faremos uma breve discussão sobre as mudanças na família. Adotaremos os modelos de família tradicional/hierárquica e pós-moderna/igualitária 
como referência para pensar a família na atualidade, pelo fato de o primeiro ser ainda um modelo de referência forte, mesmo que não necessariamente desejado como tal, e o segundo considerado como um ideal a ser alcançado. Na chamada família moderna ou "moderna 1" (Singly, 2000) (final do século XVIII até os anos 1960), os adultos estavam a serviço do grupo familiar e das crianças, cumprindo funções distintas entre homens e mulheres que visassem à felicidade do grupo. A instituição do casamento era valorizada, pois só ela era capaz de garantir a realização desses objetivos (Roudinesco, 2003; Singly, 2007). Essa família pautava-se numa lógica de grupo centrada no amor e na afeição. Hoje é tomada como referência, relembrada com nostalgia e considerada como ideal.

A partir da década de 1960, os processos de modernização, industrialização e urbanização ganham terreno no Brasil, trazendo mudanças na família. A família conjugal moderna entra em crise ao deixar transparecer os conflitos entre os valores igualitários e as práticas hierárquicas.

Nesse momento surge um modelo de família denominado de "individualista e relacional” ou "moderna 2" (Singly, 2000). Essa família, pensada como igualitária e também designada de pós-moderna (Roudinesco, 2003), não é um rompimento radical em relação à "família moderna 1", mas uma extensão já que se tem uma ainda maior ênfase no amor, ou seja, o amor se torna condição e justificativa para que os cônjuges permaneçam juntos, incrementando a atenção aos filhos. $\mathrm{O}$ processo de individualização ganha mais importância, transformando a família em um espaço privado a serviço dos indivíduos e tendo como elemento central os membros que a compõem. Suas relações são valorizadas se realizarem as satisfações de cada um dos seus membros (Singly, 2007). Nesse sentido, ela unirá dois indivíduos em busca de relações íntimas, por uma duração relativa. Em consequência, há um aumento no número de divórcios e recasamentos, tornando a transmissão da autoridade mais problemática (Roudinesco, 2003).

O exercício de autoridade espelha o modo como a família lida com a hierarquia em seu interior. Assim sendo, podemos observar que, nos variados modelos familiares, a hierarquia se faz presente, ainda que com nuances diversas. Tem-se, desse modo, uma distinção nos papéis desempenhados pelos membros da família, os quais implicam diferentes funções, responsabilidades, direitos e deveres.

No modelo da família tradicional, há uma clara distinção dos papéis segundo o gênero e a geração. Em outras palavras, homem e mulher se percebem intrinsecamente diferentes, assim como pais e filhos. Há regras 
claramente definidas para cada um com base em seus papéis, sendo as fronteiras entre situações e pessoas pouco ambíguas. A identidade de seus membros é posicional. Dessa forma, os pais têm autoridade sobre os filhos e mantêm com eles relações mais distantes e pautadas na hierarquia. Esse modelo familiar pode ser resumido em hierarquia, desigualdade e privilégios.

Assim como a sociedade contemporânea tenta romper com o padrão hierárquico, a família igualitária também o faz e valoriza os indivíduos por suas idiossincrasias. O princípio regulador das relações no interior dessa família é a equivalência, promovendo o relacionamento dos indivíduos com base no ideal de igualdade e respeito, rompendo com a ideia de que as categorias homem/ mulher e adulto(pais)/criança(filhos) sejam intrinsecamente diferentes (Heilborn, 2004; Coelho, 2007).

Apesar de haver esses dois modelos de família, o que se observa no cotidiano é que as relações familiares são mais complexas, ou seja, a família vivida é mais flexível e plural (Vaitsman, 1994), e as características de um modelo e de outro se mesclam de inúmeras maneiras, compondo famílias singulares. Esse é o desafio que se coloca nas famílias contemporâneas, o de estabelecer a hierarquia, mantendo o exercício da autoridade numa lógica individualista.

Na família hierárquica, o princípio da autoridade ébásico no estabelecimento da relação parento-filial. Assim, filhos devem obedecer às ordens parentais e reconhecer o lugar de cada um na família; vale dizer, lugar pautado na diferença. Se a autoridade é inquestionável nesse modelo, o mesmo não se pode afirmar em relação ao modelo igualitário. Caso seu princípio básico fosse levado à última instância, a autoridade não existiria nessa família. No modelo igualitário, os pais saem do seu papel tradicional para serem amigos dos filhos, deixando uma lacuna no lugar da figura da autoridade.

Um ponto de impacto dessas mudanças localiza-se no relacionamento entre pais e filhos, transformações estas que se tornam mais visíveis na adolescência dos filhos. A visibilidade nessa fase advém do fato de o sujeito buscar independência e autonomia, fazendo um movimento de individuação e separação progressiva dos pais.

\section{Adolescência e família}

A Psicologia analisa a adolescência numa perspectiva que parte do sujeito particular e de seus processos de transformação, considerando esse momento como crucial na vida do indivíduo e decisivo para seu futuro. O tempo da adolescência é mais do que um tempo cronológico, ele é o momento da 
realização das tarefas psíquicas que levam os adolescentes à elaboração de nova identidade: a identidade de adulto.

A adolescência pode ser estudada como um estágio sui generis mais que simplesmente um período transicional. Assim, não é apenas um período de cristalização e reestruturação de papéis aprendidos na infância, mas há uma atitude ativa dos adolescentes em relação à sua sociedade. Apresentase uma descontinuidade em relação à infância. Também não é apenas um período de acomodação do indivíduo às instituições sociais. Com efeito, os adolescentes podem ser tomados em sua "positividade" como agentes culturais e sociais (Dayrell, 2003). Eles têm seu status modificado pelos processos de individuação e autonomização, que redefinem relações intra e intergeracionais, como também por atributos de seus pertencimentos de classe, gênero e raça/etnia. É desse modo que os adolescentes constroem uma nova identidade (a adulta) mediada por esses atributos e pelos valores do grupo social de pertencimento.

Essa fase é também um momento de ruptura com a posição infantil de ser uma posse dos pais. Nessa mudança, a relação entre o adolescente e seus pais passa a ser pautada por uma ignorância, a dos pais, por não compreenderem seu filho, e deste, por não entender seus pais. Surge, então, um silêncio na família. Corso e Corso (1999, p. 85) afirmam que "a operação própria da adolescência é a agonia e morte dos pais reais enquanto suporte do ideal". Os pais, que eram tidos como heróis por seu filho na infância, são destituídos desse lugar, desidealizados e passam a ocupar um lugar de estranhamento frente ao filho. Por outro lado, os pais também têm dificuldade de reconhecer seu filho, pois até mesmo o corpo que ele ocupa não é mais o mesmo; a imagem da criança desaparece.

Esse estranhamento provoca um desencontro no interior da família, uma solidão, possibilitando, inclusive, a agressividade. Esta surge como uma maneira de ocupar o silêncio, ainda que não seja a única. Entretanto "não é a distância entre gerações que pode trazer a agressão que temos visto se disseminar entre pais e filhos, pensamos que é justamente o contrário. As famílias modernas tendem a viver um 'unitempo', todos 'são' da mesma geração [...]." (Corso \& Corso, 1999, p. 89). As diferenças geracionais têm tido suas fronteiras cada vez mais difusas, em que se observa, com frequência, uma tentativa de os pais estarem mais próximos de seus filhos, fazerem as mesmas atividades, usarem as mesmas roupas. Morin (citado por Pérez Islas, 2009) referiu-se, já em 1962, a um processo de "desgerontocratização", no qual os adultos não querem deixar de ser jovens. Dessa forma, a questão juvenil trata-se de uma nova classe etária que engloba não só os adolescentes, mas também as precoces crianças e os adultos. Tudo isso dificulta o processo de diferenciação 
tão necessário aos adolescentes para que possam construir uma identidade adulta e demarcar um espaço próprio no mundo.

Também no que tange à identidade, a família tradicional e a pós-moderna fornecem modelos identitários diferenciados a cada um dos membros. $\mathrm{Na}$ primeira, os modelos pautavam-se em valores e padróes de comportamentos relativamente estáveis, passados de geração a geração. $\mathrm{Na}$ segunda, há uma indefinição e ausência de modelos fixos. Há a coexistência de valores e padrões de comportamentos tradicionais e novos, portanto, muitas vezes, contraditórios. "Essa desconstrução de modelos fixos do passado, que alterou os papéis e as posições de homens e mulheres, pais e filhos, avôs e avós, alterou também as formas de relação entre as diferentes gerações na família" (RochaCoutinho, 2006, p. 101). Isso significa que, atualmente, cada família pode definir a forma como suas relações serão vividas, as bases em que se pautarão e, inclusive, o exercício de autoridade em seu interior.

\section{Família e autoridade}

Torres e Castro (2009), ao fazerem um percurso histórico sobre os sentidos da autoridade, relacionam a noção de autoridade ao conceito de fundação. Esta engloba bens, obras, objetos e, principalmente, valores, crenças e formas de ser e pensar, que constituiriam a tradição. A tradição guardaria o acervo dos antepassados e seria a base para as ações das gerações presente e futura. A autoridade faria aumentar os domínios da tradição, construindo algo novo, mas voltando ao passado herdado.

Com a Modernidade, a origem de todas as coisas passa a ser questionada, o sujeito se torna mais ativo em seu processo de vida e não há mais espaço para a tradição.

Uma verdade que escapa, que só aparece em relação a, e não mais em si, somada à noção de que o homem é iniciador de processos, faz com que olhemos a realidade como mutável, passível de transformações constantes. Neste contexto, a autoridade tende a perder força, pois não encontra mais nada em que se fundamentar ou não é mais fundamento de nada (Torres \& Castro, 2009, p. 8) [grifos das autoras].

Ao compreendermos a família como uma unidade composta por indivíduos com posiçōes distintas, vivendo um jogo de poder que se materializa na distribuição de direitos e deveres a cada um de seus membros, podemos dizer que haverá alguém na família que exercerá controle sobre os demais. O exercício da autoridade e do controle, geralmente, leva a conflitos interpessoais. 
A aporia conflito/entendimento costuma ser a tônica para a compreensão da relação pais e filhos jovens. Cicchelli (2001) aponta que, até o início dos anos 1980, a ênfase estava no conflito na relação parento-filial. A rapidez da mudança social, consequente à passagem da sociedade tradicional para a moderna, seria uma razão, pois haveria um descompasso entre os conhecimentos transmitidos pelos pais e as necessidades de inserção social adequada dos filhos ao mundo tecnológico e cultural. A descarga da tensão emocional sobre os pais, únicos adultos pertencentes ao grupo doméstico, devido à diminuição do tamanho das famílias, seria outra razão. A concorrência entre os pais e os outros agentes de socialização, como os especialistas e, primordialmente, os grupos de pares, também manteria a tensão.

A partir da década de 1980, a tendência de generalização do conflito, típica das décadas precedentes, dá lugar a uma generalização do bom entendimento entre as gerações. Cicchelli (2001) afirma que, segundo alguns autores, isso se deve à menor oposição entre socialização parental e socialização pelo grupo de pares. Essa propensão diferenciada não é consenso, já que outros autores acreditam no "adolescentrismo" ou horizontalidade da sociedade contemporânea, não reconhecendo as distinções entre adultos e jovens. Dessa maneira, os pais são responsabilizados pela perda da transmissão geracional. Eles não estariam mais exercendo o papel de educadores e a autoridade que lhes é cabida, preferindo evitar o conflito e "tornando-se cúmplices dos problemas psíquicos que afetam os adolescentes” (Cicchelli, 2001, p. 254).

A pacificação geracional também poderia estar no fato de pais e filhos compartilharem valores reivindicados pelos primeiros em sua juventude. As relações parento-filiais estariam pautadas na permissividade, tornando-se a família uma democracia familiar, orientada pelo diálogo e negociação. Dessa forma, a autoridade não teria mais lugar na família, explicando o motivo da diluição do conflito intergeracional.

Há que se pensar, então, como se dará a autoridade parental no contexto contemporâneo, considerando a desconstrução dos modelos fixos, da perda da tradição, da multiplicidade de valores e de possibilidades de vivências familiares. Ao tomarmos a família tradicional como primeiro parâmetro a ser pensado, temos que o regulador tem esse lugar reconhecido de maneira inquestionável pelos demais membros. Todavia, na família pós-moderna, pautada numa lógica igualitária, o controle pode ser questionado e, consequentemente, ser ponto de mais conflito entre os membros.

Kehl (2003) aponta que a diferença dos lugares geracionais é a única ancoragem possível da autoridade parental no contexto contemporâneo. 
Entretanto, Giberti (2005, p. 175, tradução minha) chama atenção para um risco: "inúmeros enfrentamentos geracionais estão associados com a persistência de pautas acordadas por gerações anteriores". Os adultos esperam e desejam que, ao evocarem as gerações anteriores como referência, sejam escutados pelos jovens. Entretanto, não é o que se sucede, apesar de os jovens não se desentenderem completamente, pois estão submetidos à lógica genealógica. "A sociedade que institui a juridicidade das genealogias fala ao jovem o código de obediência aos pais e de respeito a suas indicaçôes" (Giberti, 2005, p. 176, tradução minha). Essa é a origem do pacto entre as gerações.

Todavia, o que vimos atualmente é uma modificação ou deslizamento dos eixos do pacto geracional pelos jovens e seus pais. Giberti (2005) afirma que está ocorrendo uma passagem do pacto ao contrato intergeracional. Esse é regido pela reciprocidade e equivalência de pais e jovens, com o reconhecimento de suas diferenças, mas não exclusivamente pela verticalidade posta na dinâmica geracional, que afirma que os jovens devem obedecer aos mais velhos. A transformação do pacto em contrato abarca a noção de equidade. Se a ideia de pacto compreendia que os jovens eram obrigados a privilegiar a obediência, no contrato, há a presença de dois indivíduos equiparáveis.

Mas como fica a questão da autoridade parental se trabalharmos com a ideia de contrato intergeracional e não de pacto? As famílias hierárquicas pautavam-se no pacto intergeracional, a autoridade dos pais era inquestionável, e os filhos estavam submetidos a eles. Já as famílias igualitárias pautam-se na pretensão/intenção de conseguirem realizar o contrato intergeracional. Contudo, um desafio se coloca: como pais que foram educados na lógica do pacto conseguirão rompê-la para se filiarem ao contrato?

Essas questões apontam-nos algumas linhas de raciocínio. Singly (2006, p. 24) nos traz uma primeira linha, ao afirmar:

A vida privada mostra-nos que viver bem em conjunto tanto se define pelas fases em que cada membro do grupo vive no seu modo pessoal como pelos momentos de partilha comum. [...] Dado que cada pessoa reivindica diversos mundos, se generalizarmos a partir de um único indicador, de um único mundo, podemos deduzir erradamente existir um enfraquecimento dos laços.

A família tradicional pode ser pensada com base em um único indicador, o que nos permite percebê-la como unida por um laço forte. Entretanto, o custo desse laço é a perda da liberdade por seus membros. Já na família pós-moderna, os indivíduos exigem e esperam que haja vários laços, vários indicadores, o que perpassará as relações entre pais e filhos, fazendo com que construam uma 
rede que abarque os múltiplos fios existentes. Isso provoca uma insegurança no seio familiar, o que requer que os pais busquem formatos de fios que sejam (ou deem a ilusão de serem) mais sólidos. Todavia, a adolescência é um momento em que os pais podem sentir mais explicitamente um rompimento ou esgarçamento desses fios.

Em uma segunda linha de raciocínio, temos que, com as dinâmicas familiares atuais, os pai8s se sentem em dívida com seus filhos por não poderem dedicar o tempo que imaginam que deveriam à prole. Esse sentimento advém da perda da consistência imaginária conferida pela tradição, ou seja, os pais "se veem na contingência de impor limites e transmitir ideias a seus filhos por conta e risco" (Kehl, 2003, p. 174). Ao perceberem que não oferecem aos filhos a família idealizada (tradicional), sentem-se em dívida com eles, assim como "marginais com relação a uma paternidade idealizada e irrealizável" (Corso \& Corso, 1999, p. 94), escorregando de seu lugar e tornando-se incapazes do exercício da autoridade. Para Kehl (2003, p. 175),

Deste lugar mal sustentado, é possível também que os adultos não compreendam em que consiste sua única e radical diferença em relação às crianças e adolescentes, que é a única ancoragem possível da autoridade parental no contexto contemporâneo. Esta é, exatamente, a diferença dos lugares geracionais. [grifos da autora]

Nesse sentido, destacaremos, neste artigo, o exercício da autoridade em famílias de camadas médias com filhos adolescentes, discutindo a dinâmica das tomadas de decisão e os impasses para tal exercício.

\section{Método}

Trata-se de uma pesquisa qualitativa em que foram realizadas 11 entrevistas em profundidade com pais e mães da camada média de Belo Horizonte, em situação marital ou não, que tinham no momento da entrevista pelo menos um filho ou uma filha entre 14 e 19 anos, totalizando 3 mães separadas e 3 mães casadas, 3 pais separados e 2 pais casados. Considerou-se como separados aqueles sujeitos que não viviam mais uma relação marital com a mãe ou com o pai do filho ou da filha adolescente, independente de estarem casados novamente ou não. A divisão dos sujeitos em grupos de casados e separados deveu-se à necessidade de conhecer as dinâmicas e estratégias diferenciadas que podem ocorrer quando os filhos moram com o pai e a mãe conjuntamente ou apenas com um dos pais, mesmo que este ou esta esteja casado. Partiu-se do pressuposto de que pais casados teriam decisóes mais 
conjuntas ou dialogadas em relação aos filhos, enquanto pais separados teriam mais conflitos e dificuldades quanto às decisões, repercutindo na convivência com os filhos (cf. Brito, 2008). Para facilitar a leitura, os pais e as mães separados receberam nomes com a letra $S$ e os casados, com a letra $C$.

Para chegar aos entrevistados, buscaram-se indicaçóes de várias redes de conhecidos para se obter uma diversidade maior do universo pesquisado. Após o conhecimento dos objetivos da pesquisa e seus procedimentos, os sujeitos concordaram com a realização das entrevistas, com sua gravação e divulgação. Em respeito a preceitos éticos, nomes fictícios são utilizados para preservar a identidade dos sujeitos, assim como quaisquer dados que porventura venham a identificá-los.

A análise do material foi feita na perspectiva da análise do discurso, que possibilita um trabalho com as cadeias associativas produzidas pelo entrevistado, assim como seus silêncios, lapsos, esquecimentos, reticências, erros (Machado, 2002). Por isso, esse instrumento de análise é rico e serviu bem para o propósito desta pesquisa.

\section{Resultados e discussão}

A cada etapa da vida dos filhos, novos desafios e exigências são colocados em cena, e os pais precisam fazer adaptações no exercício parental. Entre os entrevistados, não houve consenso se a infância ou a adolescência é melhor para o exercício parental, mas foram unânimes em afirmar que a relação entre eles e os filhos modificou-se quando estes entraram na adolescência. Muitas dessas modificações afetam direta ou indiretamente o exercício da autoridade nas famílias.

Sarti (2004a, p. 123) argumenta que o lugar do adolescente na família é daquele que introduz "o 'outro' necessário na família, por meio de novos discursos que abalam seu discurso oficial - seja pela ruptura, pela inversão ou, mesmo, pela reafirmação deste discurso". As possíveis reações, sejam de abertura ou fechamento ante o estranho, são decisivas para as relações familiares e para o adolescente em busca de sua identidade adulta. Ainda para a construção dessa identidade, Stengel (2003) aponta a necessidade de o adolescente fazer uma separação progressiva dos pais. Ele precisa distanciarse dos pais e, nesse movimento, a autoridade, que era localizada basicamente neles, desloca-se para outros indivíduos que se tornam significativos, como professores ou pais de amigos e, principalmente, para o grupo de pares. Esse afastamento é sentido e ressentido por todos os entrevistados. Se, por um lado, o crescimento dos filhos significa que os pais ficam mais livres 
das tarefas cotidianas e podem fazer planos mais individualizados, que não necessariamente abarquem os filhos, por outro, é vivido como uma perda para os pais. $\mathrm{O}$ afastamento implica o distanciamento do contato físico e da separação do mundo do adolescente daquele dos pais.

\section{Sílvio queixa do filho mais velho:}

Está com a vida dele, vai para as festas dele, vai com os amigos dele, não participa da, como é que chama assim? Das coisas comuns que têm lá em casa, não vai para o sítio com a gente. Mas, está lá dentro, às vezes, chega, cumprimenta todo o mundo, às vezes entra para dentro do quarto e tem a vida dele lá dentro do quarto.

\section{Sara reitera:}

Então, há uma separação maior, né, uma separação até física mesmo, né. [...] Já muda até a sua forma de chegar no seu filho, sabe. É, respeitos que você tem que ter, tipo quarto trancado, né, isso aqui é meu, meu diário, né.

Pode-se perceber que o quarto é uma representação da separação de mundos. É visto como o "território" dos jovens, território no qual o controle e a autoridade parentais sofrem restriçôes (Peixoto, 2000). Considerando que esta pesquisa foi realizada com famílias de camada média, é usual que os filhos tenham um quarto exclusivo para eles. Entre os entrevistados, alguns filhos dividiam o quarto com irmãos do mesmo sexo e outros tinham um quarto próprio. Esse espaço é usado para isolar-se dos outros membros da casa, receber os amigos mais íntimos, namorar, ouvir música, usar o computador; enfim, é preservado pelos adolescentes como um espaço em que a entrada não é livre para qualquer um em qualquer hora, sendo necessário pedir permissão para entrar ali. Percebe-se que a separação dos pais não é apenas psíquica, mas, muitas vezes, há necessidade de concretizá-la objetivamente, espacialmente. A demarcação do espaço físico não deixa dúvidas do processo que o adolescente está vivendo, por mais que os pais queiram negá-lo e tenham conflitos em aceitá-lo.

O afastamento dos filhos significa também perda de influência sobre suas vidas. Ou, nos termos de Samuel,

Porque antes assim, eu fazia um movimento assim ó, sabe, com a mão, tinha um reflexo neles, sabe, imediato. Hoje não, hoje 
eu faço um movimento assim, mas às vezes não responde lá, às vezes eles não estão no meu campo de energia, entendeu? [...] E aí, eu tenho que lidar com isso também, eles estão no campo de energia, eles estão fazendo o campo de energia deles.

\section{Samuel ainda diz sobre a diferença dos filhos a partir do desenvolvimento deles:}

Eles vão crescendo assim e você vai vendo como que tem uma determinada fase que você é o sol para eles, né, eu sei direitinho, você é o todo-poderoso, sabe? [...] Então, eu acho que a partir dessa idade, nove, dez anos, já muda, você já não é tão sol, você já não é mais o perfeito, você é imperfeito também, sabe?

A ideia do sol é expressiva, pois se pode pensar que o Sol é aquele que dá luz, dá vida, possibilita o crescimento, aquece, além de ser chamado de rei. A identificação com as figuras parentais é a primeira dentre uma série que a criança viverá. Como a relação com os pais tem forte base afetiva e não só cognitiva, ela marcará profundamente o sujeito, acompanhando-o durante toda a sua vida e atravessando seus outros processos de identificação. Por isso, na infância, os pais são percebidos pelos filhos de forma idealizada, ainda que posteriormente essa imagem seja abalada, o que apontam os entrevistados. Desse modo, pode-se pensar que, se os pais são alvos de idealização e perfeição por parte dos seus filhos, essa relação que as crianças estabelecem com seus pais torna-se fonte de idealização também para os pais.

A destituição dos pais de um lugar privilegiado posto na infância pelos filhos deve-se também por os adolescentes perceberem defeitos nos pais. Consequentemente, eles se tornam críticos das atitudes e valores dos pais, colocando em xeque o exercício da autoridade. Cândida aponta isso com muita clareza: "Adolescente acha que eles são os donos da verdade, que pai e mãe não sabem nada”. Sara, que também é vítima das críticas da filha mais velha, relaciona esse comportamento com o fato de que os pais servem de modelos para os filhos e estes sentem necessidade de superá-los.

As críticas, muitas vezes, expõem uma competição entre pais e filhos. Sara sente que "Existe uma competição muito grande às vezes, né, uma necessidade assim de me superar em algumas coisas, nê". Ela conta que, em determinada época, ela e a filha tinham namorados. A filha chegou a lhe dizer: "Se você pode chegar às quatro horas da manhã com namorado, eu também posso". Ela declara que foi um período tumultuado, pois a filha queria fazer tudo que a mãe realizava e testava sua autoridade. A forma que Sara encontrou para 
resolver a questão foi recuperando sua autoridade e marcando para a filha as diferenças de idade e de papéis, inclusive apontando para a menina que ela é financeiramente dependente da mãe.

O afastamento dos filhos pode ser relacionado também à questão do controle. Conforme os filhos se afastam, o exercício de controle se torna mais difícil ou, pela primeira vez, é tornado um problema, uma vez que, no que concerne às crianças, a percepção de independência e afastamento não estavam presentes. Os pais expressam a ideia de que, na infância, há um controle absoluto, ou quase, sobre seus filhos, sabendo aonde eles vão, com quem e o que fazem. Com a entrada na adolescência, a expansão da vida social dos jovens e o movimento de separação que fazem dos pais, esse controle desaparece ou diminui consideravelmente, gerando muita angústia nos pais.

Cândida lembra um ditado, "filho criado, trabalho dobrado", para falar da diferença da infância para a adolescência dos filhos. Ela reforça a ideia da falta de autonomia e de desejo das crianças: "Quando é pequeno, a gente tem aquele trabalho, de cansar e tudo, mas está ali do lado, né, faz o que você quer. Agora, já adolescente, não". Essa ideia é compartilhada por Simone: "É que você preocupa menos, que eles estão ali, tudo ali com a gente. Não está naquele periodo de sair sozinho, né. Eu acho que é isso que a mãe pensa, está comigo, está aqui, né, debaixo da asa". A questão do controle não é específica das mães, como diz Caio: "Com criança, a gente é que guia a criança. O adolescente começa a andar por si próprio, né, isso é que a gente fica assim meio..."

Para compreender melhor o que significa o controle para os pais, recorreremos a Sílvio, que expressa ser "Muito mais difícil você estar lidando com quem tem já um desejo e acha que pode tomar as decisóes todas". Segundo ele, o que faz com que os adolescentes decidam por si mesmos é ter desejo.

No ideário da família igualitária, as crianças cada vez mais têm sua vontade colocada em cena. Esse modelo familiar possibilita às crianças serem tratadas por sua individualidade, ou seja, têm voz na família, seus desejos são respeitados e colocados, muitas vezes, em prática. Aquela criança passiva, obediente, que abaixa a cabeça para os pais vai cedendo lugar a uma mais ativa, que diz o que quer, mais independente e autônoma. Ao considerar as crianças como desejantes, não se pode nem ignorar seus desejos e menos ainda fingir que eles não existem. Tem-se de respeitar e aceitar essa característica do indivíduo. Ainda que, entre os entrevistados, nenhum deles viva estritamente esse modelo familiar, seu ideário faz parte do cotidiano dessas famílias, atravessando as relaçôes paterno-filiais. Por isso, é interessante notar que, pela fala dos pais, 
parece que as crianças lhes obedeciam completamente, fazendo tudo que eles mandavam, que é contraditório com o discurso que sustentam sobre o modo de relacionamento com os filhos, pautado no diálogo.

A descoberta de que os filhos não são mais "suas crianças" também pode indicar haver um temor pelos pais de serem ultrapassados por eles, conforme os filhos estão em um processo de desenvolvimento e os pais podem estar lamentando pelo seu tempo já passado. Desse modo, os pais podem posicionarse de forma ambivalente frente aos filhos, desejando que cresçam e se tornem independentes, por um lado, e reforçando comportamentos de dependência, por outro. Além disso,

O processo de separação do jovem acentua a questão da redistribuição do poder no grupo familiar. A crescente individuação do filho o torna cada vez mais capaz de assumir suas escolhas e decisões. O poder decisório entra em declínio, fazendo com que pais inseguros sintam um esvaziamento em suas funções (Oliveira, 2000, p. 44).

Singly (2000) afirma que a família educa seus filhos hoje, enfatizando a iniciativa e a autonomia, e deprecia a obediência. Vivemos em uma cultura em que a autonomia e a independência são valores centrais e exaltados. Desse modo, os pais transmitem a seus filhos a ambição de não repetir a vida e o status dos adultos que os engendraram (Calligaris, 2000). Nesse momento, a autoridade dos pais pode ser destituída ou, ao menos, minada conforme os filhos sentem que, para corresponderem aos valores transmitidos, têm que superar os pais. A superação implica um questionamento da autoridade parental.

A ênfase na iniciativa e na autonomia traz outra questão: a autossuficiência. Os adolescentes creem que sabem tudo e se sentem com autonomia para tomar decisões, não cabendo um controle externo, ou seja, o controle parental. Nos termos de Sílvio:

O filho adolescente, ele tem primeiro uma visão de mundo pretensamente autossuficiente, né, pretensamente, porque embora ele ache que ele já sabe tudo, né, que ele pode tudo, ele não sabe tudo e não pode tudo, ele não é independente o suficiente para tomar todas as decisões, mas ele tem essa percepção.

O controle suscita algumas questôes. Um primeiro ponto a ser considerado é que a possibilidade de deixar que o outro se afaste está diretamente ligada à confiança que se tem nele. A paternidade e a maternidade têm sofrido uma série de alteraçôes nos últimos tempos e pode ser atestada significativa 
diversidade entre a geração dos entrevistados e a de seus pais. As relaçôes eram mais pautadas na hierarquia, na diferença e na autoridade dos pais, havendo uma relação mais distante entre pais e filhos. As normas e os valores que são introjetados no seio da família permanecem com os sujeitos ao longo da vida, atuando como base para a tomada de decisões e atitudes. Mesmo na fase adulta, a família continua dando sentido às relações entre os sujeitos e sendo um espaço em que as experiências vividas são elaboradas (Sarti, 2004b).

A geração dos entrevistados faz um rompimento com os modelos de parentalidade vivenciados quando filhos, e, muitas vezes, ficam sem parâmetros bem definidos para serem pais e mães, ou seja, não têm como recorrer à tradição (Kehl, 2003). Os modelos de seus pais já não lhes servem perfeitamente e outros modelos, então, têm de ser construídos. Tudo isso é vivido com dificuldades e inseguranças pelos entrevistados, o que pode gerar falta de confiança nos filhos, por não ter segurança na educação que lhes deram.

Somado a isso, há que se considerarem as transformações nas famílias quanto ao processo decisório. Se, na família tradicional, as decisões que tocavam os filhos e a própria família eram exclusivas dos pais, hoje vemos mudanças. Os filhos estão autorizados a opinar e contribuir diretamente na decisão. Implicar os filhos adolescentes nas decisões cotidianas é um exercício de autonomia para eles e de responsabilidade por suas atitudes e desejos. Cláudio e Cândida falam da inclusão de seus filhos em decisões familiares. Os tópicos em questão são aqueles que atingem diretamente os meninos. Um exemplo comum a eles é as férias familiares, em que os filhos têm influência decisiva sobre a definição do local.

$\mathrm{O}$ fato de os filhos poderem decidir onde passar as férias não significa que eles possam tomar outras decisões à revelia dos pais. A noção de igualdade que pauta o discurso dos pais é colocada à prova pela desigualdade situacional entre estes e seus filhos. A desigualdade situacional relativiza a participação dos filhos no processo de tomada de decisão, uma vez que, embora vazado pelo ideal igualitário, a situação de desigualdade entre pais e filhos é real.

Além de uma participação mais direta nas resoluções, tal como colocado acima, os filhos podem participar de forma indireta, qual seja, a de não aceitar e não cumprir a decisão dos pais, confrontando a autoridade parental. Observa-se isso, principalmente, nos casos de pais separados, em que a distância que um dos pais estabelece com os filhos faz com que ele não seja percebido como figura de autoridade reconhecida e, por isso, não haveria 
necessidade de obedecê-lo. Sara, por exemplo, conta que suas filhas não respeitavam muito o pai, porque ele estava distante delas e sua autoridade ficou "bem desgastada".

Essa afirmação de Sara remete à desigualdade condicional entre pais e mães. Ela é marcada pela retórica da presença, ou seja, há um discurso de que a presença do pai ou da mãe é imperativa para a tomada de decisão e do exercício da autoridade. Pais e mães separados, que têm a guarda de seus filhos, afirmaram que nem sempre recorrem ao ex-cônjuge para tomar decisōes relativas aos filhos. Essa retórica prepondera na infância dos filhos, mas se transforma na adolescência. $O$ fato de o filho entrar em cena e se posicionar frente à decisão, colocando em xeque a autoridade do pai ou da mãe parece ser significativo nessa transformação.

Tradicionalmente, o papel de autoridade, daquele que põe limite, é socialmente dado ao pai. Esse é quem tem a função de lei no interior da família e, consequentemente, tem o direito de cobrar dos filhos comportamentos considerados adequados por ele. Esse papel éapontado pelas mães entrevistadas, principalmente aquelas separadas. Elas falam do papel de autoridade como algo que deve ser exercido pelo pai e buscam-no, geralmente, em momentos de crise.

Quando a filha mais velha começa a questionar sua autoridade e não querer obedecê-la, Sara busca ajuda no ex-marido para que exerça sua função de autoridade, ou seja, cumpra seu papel de pai. Ela também passa a implicálo mais quanto às decisões necessárias em relação às filhas. $\mathrm{O}$ mesmo se dá com Solange. Entretanto, o ex-marido dela tem "pouca autoridade" sobre as filhas, principalmente por ser pouco participativo no cotidiano e não saber compreendê-las, isto é, não entender a lógica e o mundo dos adolescentes, segundo a mãe.

Simone também compreende a função de autoridade como fazendo parte do papel paterno. Ela aponta a atual falta de autoridade do ex-marido com os filhos, o que, em sua perspectiva, é fruto de dois fatores: a ausência dele no cotidiano dos meninos, não participando e não se envolvendo em suas vidas, e o fato de não ter o monopólio da provisão.

Essas mães tentam manter uma relação com seus filhos pautada na negociação e na amizade, ou seja, um tipo de relacionamento marcado pela tendência à igualdade e ao diálogo, em que as diferenças hierárquicas tendem a ser desconsideradas ou, pelo menos, minimizadas. Trazer o pai para o lugar da autoridade pode ser uma forma que as mães encontram para manter essa relação considerada como mais positiva e satisfatória com seus filhos, 
enquanto o lado negativo ficaria com o pai. Especialmente no caso das mães separadas, isso parece ser significativo, pois há uma queixa de que elas são "que dá o pão, o que dá o castigo. É pesado, você fica sem moral, você fica desgastada, não é?" (Solange). Então, quando os pais entram em cena exercendo o papel de autoridade, ou seja, aquele que coloca limite nos filhos e, muitas vezes, os impedem de fazer o que desejam, eles assumem o lado do "castigo" e elas o do "pão", facilitando a relação materno-filial.

Apesar de muitos pais não conseguirem criar uma atmosfera de lar sozinhos, ou seja, ter uma casa com espaço organizado para receber os filhos, continuam a ser considerados por suas ex-esposas como os principais disciplinadores dos filhos.

Vale ressaltar que o discurso de Samuel e Sílvio, pais que têm a guarda de seus filhos, difere daquele das mães separadas. Os dois afirmam que as mães de seus filhos são ausentes no cotidiano dos meninos, pouco participando e, inclusive, encontrando-se com eles. Sílvio parece não fazer muito esforço para que essa situação se modifique e toma sozinho as decisões relativas aos filhos. Samuel acredita que seria bom se a ex-esposa participasse mais da vida dos filhos, mas afirma que a distância dela lhe facilita a tomada de decisões, pois não há necessidade de haver negociação entre os pais.

Isso leva a perceber que as atitudes em relação às decisões são dinâmicas, variando nos diversos momentos da vida dos filhos e mesmo da vida do pai ou da mãe, assim como da percepção que passam a ter dos problemas que são colocados em cena. Também aponta para a dissolução ou o esmaecimento da dicotomia pai distante, figura de autoridade e mãe próxima, figura de afeto (Pratta \& Santos, 2007).

\section{Considerações finais}

A família contemporânea tem trazido desafios para seus membros. Pela pluralidade em suas formas e flexibilidade em suas regras e desempenho de papéis, as relações familiares têm de ser reinventadas e negociadas cotidianamente. Essas reinvenções e negociações são atravessadas pelas contradiçóes que os modelos hierárquico e igualitário trazem e pelas transformaçóes que têm tido lugar em nossa sociedade atual. Pais que foram criados em famílias primordialmente hierárquicas buscam educar seus filhos de forma mais igualitária. Empregam um estilo participativo-igualitário baseado no diálogo, afeição e compreensão.

Por mais que, em vários momentos, a lógica tradicional seja buscada para 
pautar a família e ajudá-la a resolver determinadas situações, especialmente as conflitivas e as que requerem o exercício da autoridade de forma mais explícita, essa lógica já não cabe mais. Os indivíduos de hoje não se parecem nada com os das sociedades tradicionais. A família contemporânea reúne sujeitos que pautam suas relaçôes na individualidade, liberdade, possibilidade de escolhas e equivalência. Por isso, a relação parento-filial também não pode ser retomada àquela anterior, tradicional, pois os sujeitos não a suportariam. Fica o impasse de como resolver essa situação.

Esse impasse, como se discutiu e se ouviu dos entrevistados, é potencializado na adolescência dos filhos. Como uma das tarefas dessa fase é a construção de uma identidade adulta, o jovem deve renunciar a seus papéis infantis, abarcando o abandono de um tipo de relação estabelecida com os pais. Esse processo demanda modificações na família, havendo necessidade de adaptação das regras e, consequentemente, de ajustamento no exercício da autoridade.

Há outro impasse colocado. Se a diferença dos lugares geracionais é apontada como a única ancoragem possível da autoridade parental no contexto contemporâneo, parece-nos então impossível, ou quase, a manutenção do contrato intergeracional, já que este implica em equiparação dos sujeitos envolvidos. A viabilidade do contrato intergeracional requer novas formas de viver a família e em família. Podemos pensar que o exercício da autoridade terá de ser negociado cotidianamente, considerando cada uma das situaçôes colocadas em cena.

\section{Referências}

Brito, L. M. T. (2008). Alianças desfeitas, ninhos refeitos: mudanças na família pós-divórcio. In: Brito, L. M. T. (org.). Famílias e separaçôes: perspectivas da Psicologia jurídica. (pp. 17-47). Rio de Janeiro: Eduerj.

Calligaris, C. (2000). A adolescência. São Paulo: Publifolha.

Cicchelli, V. (2001, julho-dezembro). Repensar os laços entre pais e jovens adultos fora da aporia conflito/entendimento. Interseçôes - Revista de Estudos Interdisciplinares, (3) 2, 247-265.

Coelho, S. V. (2007). Família contemporânea e a concepção moderna de criança e adolescente. In: Instituto da Criança e do Adolescente (org.). 
Criança e adolescente: prioridade absoluta. (pp. 189-228). Belo Horizonte: Editora PUC Minas.

Corso, M. \& Corso, D. L. (1999). Game over. In: Associação Psicanalítica de Porto Alegre. Adolescência entre o passado e o futuro. (pp. p. 81-95). Porto Alegre: Artes e Ofícios.

Dayrell, J. (2003, dezembro). O jovem como sujeito social. Revista Brasileira de Educação [on-line], 24, 40-52. Recuperado em 24 de junho de 2009, de http://www.scielo.br/pdf/rbedu/n24/n24a04.pdf.

Giberti, E. (2005). La familia, a pesar de todo. Buenos Aires: Ediciones Novedades Educativas.

Heilborn, M. L. (2004). Dois épar. Rio de Janeiro: Garamond.

Kehl, M. R. (2003). Em defesa da família tentacular. In: Groeninga, G. C., Pereira, R. C. (orgs.). Direito e psicanálise: rumo a uma nova epistemologia. (pp. 163-176). Rio de Janeiro: Imago.

Machado, M. N. M. (2002). Entrevista de pesquisa: a interação pesquisador/ entrevistado. Belo Horizonte: C/Arte.

Oliveira, I. M. D. A. (2000). De quem éo vestibular?: a mãe frente à diferenciação do filho. Dissertação de Mestrado, Programa de Pós-graduação em Psicologia Clínica, Universidade Católica de Pernambuco, Recife.

Peixoto, C. E. (2000). Avós e netos na França e no Brasil: a individualização das transmissões afetivas e materiais. In: Peixoto, C. E., Singly, F., Cicchelli, V. (orgs.). Familia e individualização. (pp. 95-111). Rio de Janeiro: FGV.

Pérez Islas, J. A. (2009). Juventude: um conceito em disputa. In: Guimarães, M. T. C. e Sousa, S. M. G. (orgs.). Juventude e contemporaneidade: desafios e perspectivas. (pp. 17-46). Goiânia: Cânone.

Pratta, E. M. M., Santos, M. A. (2007, agosto). Família e adolescência: a influência do contexto familiar no desenvolvimento psicológico de seus membros. Psicol. Estud. [on-line], (12) 2. Recuperado em 20 de junho de 2010, de http://www.scielo.br/scielo.php?pid=S1413.

Rocha-Coutinho, M. L. (2006). Transmissão geracional e família na contemporaneidade. In: Barros, M. L. Família e geraçôes. (pp. 90-106). Rio de Janeiro: FGV. 
Roudinesco, E. (2003). A família em desordem. Rio de Janeiro: Jorge Zahar.

Sarti, C. A. (2004a). O jovem na família: o outro necessário. In: Novaes, R. \& Vannuchi, P. (orgs.). Juventude e sociedade: trabalho, educação, cultura e participação. (pp. 115-129). São Paulo: Fundação Perseu Abramo.

Sarti, C. A. (2004b). A família como ordem simbólica. Psicologia. USP [online], 15 (3). Recuperado em 20 de junho de 2010, de http://www.scielo.br/ pdf/pusp/v15n3/24603.pdf.

Singly, F. (2000). O nascimento do "indivíduo individualizado" e seus efeitos na vida conjugal e familiar. In: Peixoto, C. E., Singly, F., Cicchelli, V. (orgs.). Familia e individualização. (pp. 13-19). Rio de Janeiro: FGV.

Singly, F. (2006). Uns com os outros. Lisboa: Instituto Piaget.

Singly, F. (2007). Sociologia da família contemporânea. Rio de Janeiro: FGV.

Stengel, M. (2003). Obsceno éfalar de amor?: as relaçôes afetivas dos adolescentes. Belo Horizonte: Editora PUC Minas.

Torres, M. C. E., Castro, L. R. (2009, abril). Resgatando e atualizando os sentidos da autoridade: um percurso histórico. Paidéia (Ribeirão Preto) [online], (42). Recuperado em 20 de junho de 2010, de http://www.scielo.br/ pdf/paideia/v19n42/11.pdf.

Vaitsman, J. (1994). Flexiveis e plurais: identidade, casamento e familia em circunstâncias pós-modernas. Rio de Janeiro: Rocco. 